live births, a ratio of 1:4. This was equivalent to a total period fertility rate of 1.72 births (less than the population replacement level of 2.2) and a total period abortion rate of 0.44 abortions over a woman's lifetime. Total period fertility rates showed a 1.8 -fold variation (1.26 to 2.32) and total period abortion rates a 4.2-fold variation ( 0.26 to 1.09 ) between district health authorities. Total period abortion rates were highest in London and possibly showed some movement between districts of women seeking a termination.

On the basis of rates in 1995, a woman in England will have an average of 2.16 pregnancies during her lifetime, of which $0.44(20.4 \%)$ will result in an abortion. Interdistrict variation in the mean number of pregnancies ranged from 1.74 to 3.31 , with $13 \%-44 \%$ being aborted (figure). The comparative contribution of fertility and abortion to total period pregnancy rate varied regionally-for example, whereas women in Bradford and Croydon had a similar number of pregnancies (2.37), the ratio of live births to abortions was 2.06:0.31 and 1.72:0.66 respectively. Both total period pregnancy rate (3.31) and total period fertility rate (2.32) were highest in East London and the City District Health Authority, which also had one of the highest total period abortion rates nationally $(0.99)$. In contrast, Camden and Islington had the third lowest total period fertility rate nationally (1.53) and the second highest total period abortion rate (1.04).

About 20\% of abortions occur in women under 20 , among whom $40 \%$ of pregnancies are terminated; the proportion in parts of London and the southeast is half to two thirds.

\section{Comment}

One in five pregnancies in England results in a termination, giving a mean lifetime abortion rate of 0.44 per woman, which is higher than a decade ago. ${ }^{1}$ Most women having abortions are young (under 30), single, and childless. ${ }^{2}$ More women (26.9\%) are having repeat abortions..$^{23}$ Not practising safe sexual intercourse is associated with abortion, testing for HIV, and treatment for sexually transmitted diseases. ${ }^{4}$ Contraceptive use is associated with social class, and abortion rates rise with deprivation. ${ }^{4}$ These factors indicate the need and potential for targeted, preventive interventions.

Globally, illegal abortions are an important cause of morbidity and mortality among women of reproductive age, particularly in developing countries. ${ }^{5}$ High fertility and abortion rates in developing countries can be readily explained, but high abortion rates in affluent populations of low fertility with ready access to contraception are less easy to rationalise. Women in all societies need access to safe, legal abortion services. With the Abortion Act 1967, the United Kingdom led other European countries in reforming abortion legislation. As in the Netherlands, there is a need to target the causes of unwanted pregnancy through more effective education and contraceptive services. This will also reduce the costs of abortion and improve sexual health.

The concepts used in this paper were derived from Population Health Outcome Indicators: a Feasibility Study and Public Health Common Data Set, both published by the Department of Health.

Funding: None.

Conflict of interest: None.

1 Clarke M. Fertility and legal abortion in England and Wales: performance indicators for family planning services. BMJ 1988;297:832-3.

Office for National Statistics. Abortion statistics. HMSO: London, 1996. (Series AB No 21.)

3 Botting B. Trends in abortion. Popul Trends 1991;64:19-29.

4 Johnson AM, Wadsworth J, Wellings K, Field J. Sexual attitudes and lifestyles. Oxford: Blackwell Scientific, 1994.

5 Kulczycki A, Potts M, Rosenfield A. Abortion and fertility regulation. Lancet 1996;347:1663-8.

(Accepted 16 December 1997)

\title{
Embryonic abnormalities at medical termination of pregnancy with mifepristone and misoprostol during first trimester: observational study
}

\author{
G Blanch, S Quenby, E S Ballantyne, C M Gosden, J P Neilson, K Holland
}

Department of Obstetrics and Gynaecology, University of Liverpool, Liverpool L69 3BX G Blanch, senior registrar S Quenby, lecturer E S Ballantyne, research fellow C M Gosden, professor of medical genetics

J P Neilson, professor of obstetric and gynaecology

continued over

BMJ 1998;316:1712-3
Accurate data on the incidence and nature of embryonic and fetal abnormality during the first trimester and of non-viable pregnancy are needed so that women who have experienced miscarriages can be counselled, and abortion and early prenatal diagnostic services can be improved. New medical techniques for abortion in the first trimester ${ }^{1}$ enabled us to collect and analyse data on undamaged first trimester pregnancies.

\section{Subjects, methods, and results}

Between November 1994 and August 1996, 506 healthy women chose medical termination of their pregnancy before nine weeks' gestation in the dedicated day care abortion unit of the Liverpool Women's Hospital. Women attended twice (firstly for oral mifepristone and then for oral misoprostol), and most aborted after receiving misoprostol and while still in the unit. Altogether, 293 passed products of conception in the day care unit (all within six hours of receiving misoprostol); 223 of these had given informed consent to study of the tissues. Women who were ineligible for study included 76 who had passed products of conception after receiving mifepristone but before readmission to the day care unit for misoprostol and a further 127 who passed products after discharge from the day care abortion unit. In only 10 women did the medical termination of pregnancy fail.

All specimens were examined macroscopically on the day of termination and fixed in 4\% paraformaldehyde. The embryos that appeared structurally abnormal on macroscopic examination were further examined histologically. Strict criteria were used to distinguish structural abnormality from traumatic damage. Agreement among three investigators (GB, $\mathrm{SQ}$, and $\mathrm{ESB}$ ) was required before a classification was 


\begin{tabular}{lc}
\hline Abnormalities in 206 embryos studied & $\begin{array}{c}\text { No of } \\
\text { embryos }\end{array}$ \\
Abnormality & 121 \\
\hline None & \\
\hline Non-viable pregnancies & 33 \\
\hline Anembryonic; intact gestation sacs & 15 \\
\hline Ruptured sac (no embryo present) & 15 \\
\hline Resorbing & \\
\hline Structural abnormalities & $5 \dagger$ \\
\hline Neural tube defect: & $2 \dagger$ \\
\hline Open posterior neuropore & $3 \dagger$ \\
\hline Open anterior neuropore & $6 \dagger$ \\
\hline Encephalocele & $3 \dagger$ \\
\hline Abdominal wall defectsł & $2 \dagger$ \\
\hline Facial cleft & 1 \\
\hline Failure of body axis rotation severely disorganised (no somites) & 1 \\
\hline Hydropic & 1 \\
\hline Congested & 39 \\
\hline TRAP twins (one without a head) & 72 \\
\hline Total No of abnormal embryos & \\
\hline Total No of potentially non-viable pregnancies & \\
\hline TRAP & \\
\hline
\end{tabular}

TRAP=twin reversed arterial perfusion.

*Embryos that were disproportionately small compared with their gestation sac and contained necrotic tissue.

†Including some embryos with multiple abnormalities.

‡Part of the gastrointestinal tract outside the abdominal wall inconsistent with physiological herniation.

determined. Two hundred and six specimens containing products of conception were collected and the findings recorded (table 1).

Patients were aged between 16 and 41 (mean 25) years; the incidence of abnormality was evenly spread across all ages. Forty women were students, 41 were unemployed, and 31 were housewives; the rest were employed in the service industry (39), as health professionals (20), in secretarial posts (16), or in other posts (19).

\section{Comment}

This study found a potential loss rate for embryos with structural abnormalities or other non-viable conditions of $34 \%$, which is higher than the frequently quoted rate of spontaneous miscarriage for "clinical" pregnancies of $15 \% .{ }^{2}$ However, it is difficult to calculate the true rate of spontaneous miscarriage as many women may miscarry at home without seeking medical help. ${ }^{3}$ We collected tissue from $44 \%$ of women, and it is impossible to know whether their abnormality rate reflected that of the whole population; however, if anything, it is likely to represent an underestimation as minor abnormalities might not have been detectable at this stage of pregnancy. Also, abnormal pregnancies might be more susceptible to abortion after mifepristone has been administered and thus to abort before misoprostol ingestion (thereby pre-empting inclusion in our study). We have no reason to believe that mifepristone would itself contribute to the structural changes as abortion occurs within only 72 hours of exposure to the drug, whereas the abnormalities must have occurred much earlier in the gestation. None of the women reported taking any drugs, although recreational drug use may have been a cause of some abnormalities. ${ }^{4}$ We anticipate that the incidence of neural tube defects in a population of planned pregnancies would be significantly reduced by the ingestion of folic acid at the time of conception and for the first 12 weeks of pregnancy. ${ }^{5}$ These findings highlight the importance of encouraging women to take folate supplements around the time of conception and to avoid potential teratogens. In our study, ultrasound examination would have identified the 48 non-viable pregnancies. These women would not have needed a termination of pregnancy if an accurate diagnosis had been made, thus reducing pressure on abortion services and relieving a burden of guilt among the women.

Our findings are unexpected but on balance probably reflect the true loss rate in pregnancies. To our knowledge, this is the first report of detailed studies of embryonic abnormality after early medical termination of pregnancy.

We thank Mr G M Kidd, consultant in charge of the day care abortion services for his support and for his permission to examine the fetal material.

Contributors: GB and SQ initiated and coordinated the formulation of the primary study hypothesis; discussed core ideas; and participated in the collection and examination of specimens, the analysis and interpretation of data, and the writing of the paper. GB and $\mathrm{SQ}$ will also act as guarantors for the paper. ESB discussed core ideas and participated in the collection and examination of specimens. $\mathrm{KH}$ participated in the collection and examination of specimens. CMG discussed the core ideas. JPN agreed the funding for the project, discussed core ideas, and contributed to drafts of the manuscript.

Funding: ESB was supported as a clinical research fellow by the British Brain and Spine Foundation.

Conflict of interest: None.

1 Lelaider C, Baton-Saint-Mleux C, Fernandez H, Bourget P, Frydman. Mifepristone (RU486) induces embryo expulsion in first trimester non-developing pregnancies: a prospective randomized trial. Hum Reprod $1993 ; 8: 492-5$.

2 Kline J, Stein Z. The epidemiology of spontaneous abortion. In: Huisjes HJ, Lind T, eds. Early pregnancy failure. New York: Churchill Livingstone, 1990:240-56.

3 Everett C. Incidence and outcome of bleeding before the 20th week of pregnancy: prospective study from general practice. $B M J$ 1997;315:32-4

4 Hume FH, Gingras JL, Martin LS, Hertzberg BS, O'Donnell K, Killam A P. Ultrasound diagnosis of fetal anomalies associated with in utero cocaine exposure: further support for cocaine induced vascular disruption teratogenesis. Fetal Diagn Ther 1994;9:239-45.

5 Wald NJ. Folic acid and neural tube defects: the current evidence and implications for prevention. Ciba Found Symp 1994;181:192-208. (Accepted 22 December 1997)

\section{Endpiece}

\section{Alternative definitions}

Diaphragm: A muscular partition separating disorders of the chest from disorders of the of the bowel.

Ambrose Bierce, The Cynic's Word Book (1906), subsequently titled The Devil's Dictionary
Day Care Abortion Unit, Liverpool Women's Hospital, Liverpool K Holland, sister

Correspondence to: Dr Blanch

SQuenby@liv.ac.uk 